\title{
PENDEKATAN FUZZY-QUALITY FUNCTION DEPLOYMENT DALAM PEMILIHAN SUPPLIER
}

\author{
Suhartini \\ Jurusan Teknik Industri \\ Institut Teknologi Adhi Tama Surabaya \\ Email : ttitin63@yahoo.com
}

\begin{abstract}
$\mathrm{P}$ T. Liku Telaga is one of the companies engaged in chemical industry production base with sulfuric acid and aluminum sulfate. To be able to produce a product according to customer's spesification, PT. Liku Telaga wanted to make improvements in the process, especially in procurement division. Where it relates to the process of selecting suppliers for the supply of raw materials in the production process. Problems encountered in this study is to determine the supplier selection and allocation of orders in accordance with the company spesification. Fuzzy Method-Quality Function Deployment is used to measure supplier performance. The purpose of this research is to be able to meet optimal solutions in selecting suppliers accordance to company criteria. Score each supplier sulfur is PT. Ocean area (Singapore) with a score of 200.8, Standard Chemical Corp. Pte.Ltd (Singapore) with a score of 164.3, PT. Yosomulyo Jajag (Surabaya) with a score of 160.3 and CV. Archindo (Gresik) with a score of 152.0. Score of each supplier of aluminium hydroxide is Hindalco Industries Limited (India) with a score of 219.0, PT. Bisindo Kencana (Jakarta) with a score of 186.0, Sumitomo (Brazil) with a score of 165.9, and Chemindus SDN BHD (Malaysia) with a score of 135.8 .
\end{abstract}

Keywords: Quality Function Deployment (QFD), Fuzzy Set, Supplier Selection.

\section{PENDAHULUAN}

\section{Latar Belakang}

Seiring dengan pasar yang semakin meng-global dan munculnya teknologi informasi, persaingan didunia bisnis semakin ketat. Agar dapat survive dalam era kompetisi maka perusahaan berupaya untuk meningkatkan performansinya dalam rangka menghasilkan suatu output yang optimal. Output yang optimal adalah output yang mampu memenuhi keinginan konsumen.

Menurut Bevilacqua (Bevilacqua, 2006) peran supplier dalam supply chain management sangat penting untuk ditingkatkan. Keputusan dalam pemilihan supplier harus dengan beberapa kriteria, sehingga dapat mempermudah dalam mengambil keputusan. Dalam perusahaan, diantara $50-90 \%$ tugas dari bagian pengadaan yang paling penting adalah pembuat keputusan dalam strategi pengadaan dan operasional untuk menentukan profitabilitas. Pengembangan yang dapat dilakukan secara sistematik dan transparan dalam menentukan pembelian dengan melakukan pemilihan supplier.

Pemilihan supplier menjadi salah satu aktifitas yang sangat penting. Hal ini berkaitan dengan tujuan perusahaan untuk mampu membuat produk yang berkualitas.

Dalam penelitian ini akan menggunakan metode Fuzzy-QFD untuk pengukuran performansi masing-masing supplier dimana perusahaan dapat menentukan beberapa kriteria dalam pemilihan supplier. QFD adalah metode perencanaan yang terstruktur untuk menentukan keinginan dan kebutuhan konsumen dan melakukan evaluasi secara sistematis untuk memuaskan konsumen. Penggunaan teori fuzzy set memberi fleksibilitas untuk menampung ketidakpastian akibat samarnya informasi yang dimiliki maupun unsur preferensi yang subjektif yang dapat digunakan dalam masalah pengambilan keputusan.

Dalam perhitungan dengan fuzzy-QFD maka dapat diketahui atribut-atribut dalam pemilihan supplier dan rangking masing-masing supplier. Namun dalam perhitungannya masih belum mempertimbangkan kendala yang ada dalam pemilihan supplier. Sedangkan dalam kondisi nyata, biasanya perusahaan dihadapkan 
pada konstrain-konstrain yang membatasinya.

\section{Perumusan Masalah}

Berdasarkan uraian diatas maka permasalahan yang dapat dirumuskan adalah "Bagaimana menentukan pemilihan supplier yang sesuai dengan kriteria perusahaan".

\section{Tujuan Penelitian}

Penelitian ini dilakukan dengan mengarah pada tujuan yang ingin dicapai, yaitu agar mampu menghasilkan solusi optimal dalam pemilihan supplier penerima order yang memenuhi beberapa fungsi objektif dan sesuai dengan kriteria perusahaan.

\section{Manfaat Penelitian}

Setelah dilakukan penelitian ini diharapkan akan diperoleh manfaat sebagai berikut : (1) Penelitian diharapkan menghasilkan suatu rancangan sistem untuk menentukan prioritas supplier penerima order. (2) Memberikan gambaran tentang penentuan prioritas supplier dengan metode Fuzzy-Quality Function Develoyment.

\section{Batasan Masalah}

Batasan yang digunakan untuk memfokuskan penelitian ini adalah :

(1) Obyek penelitian dilakukan di bagian pengadaan. (2) Perancangan sistem pemilihan supplier hanya berlaku di PT. Liku Telaga.(3) Proses pemilihan supplier hanya dilakukan pada supplier untuk produk aluminium sulfat yaitu sulfur dan aluminium hidroksida. (4) Data kebutuhan sulfur dan aluminium hidroksida diambil berdasarkan kebutuhan enam bulan yaitu dari bulan JanuariJuni 2009.

\section{Asumsi Penelitian}

Asumsi yang digunakan dalam penelitian ini adalah: (1) Kebijakkan perusahaan yang berkaitan dengan sistem pengadaan tidak mengalami perubahan. (2) Hubungan antar respon teknis pada house of quality tidak di fuzzy-kan.

\section{Metodologi Penelitian}

Kegiatan awal dari penelitian ini adalah melakukan pengamatan dan pertimbangan terhadap pemasalahan pada bagian pengadaan.

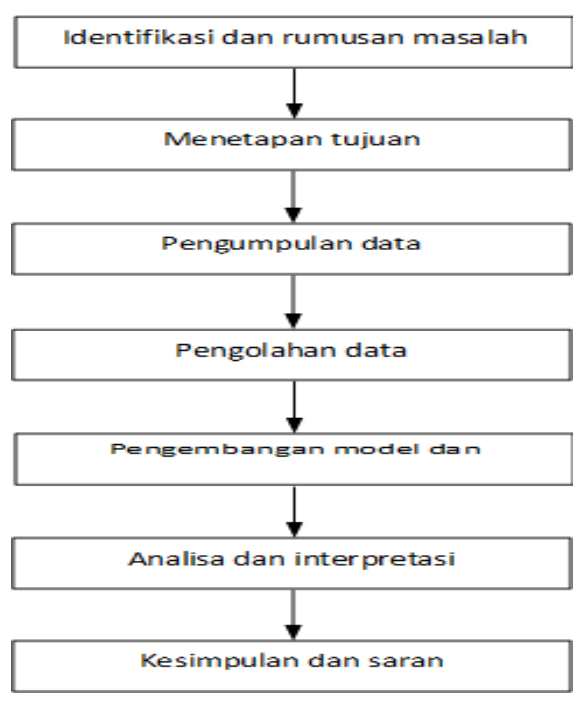

Gambar 1. Tahapan penelitian

\section{PEMBAHASAN}

a. Proses pemilihan supplier yang dilakukan oleh PT. Liku Telaga

Kriteria-kriteria yang selama ini digunakan untuk mengevaluasi supplier di PT. Liku Telaga dapat dilihat pada tabel 1.

Tabel 1. Daftar nilai masing-masing kriteria untuk mengevaluasi supplier

\begin{tabular}{|c|c|c|}
\hline Kriteria & Nilai & Keterangan \\
\hline \multirow{4}{*}{ Mutu } & 100 & $\begin{array}{l}\text { Barang dan produk dalam kondisi } \\
\text { baik }\end{array}$ \\
\hline & 90 & $\begin{array}{l}\text { Barang dan produk dalam kondisi } \\
\text { cukup baik }\end{array}$ \\
\hline & 80 & $\begin{array}{l}\text { Barang dan produk dalam kondisi } \\
\text { kurang baik }\end{array}$ \\
\hline & 70 & $\begin{array}{l}\text { Barang dan produk dalam kondisi } \\
\text { sangat kurang baik }\end{array}$ \\
\hline \multirow{4}{*}{ Harga } & 100 & $\begin{array}{l}\text { Harga yang paling murah dengan } \\
\text { kwalitas barang yang baik }\end{array}$ \\
\hline & 90 & $\begin{array}{l}\text { Harga yang murah dengan kwalitas } \\
\text { barang vang baik }\end{array}$ \\
\hline & 80 & $\begin{array}{l}\text { Harga yang sama dengan pasaran dan } \\
\text { kwalitas barang yang baik }\end{array}$ \\
\hline & 70 & $\begin{array}{l}\text { Harga yang sama dengan pasaran dan } \\
\text { kwalitas barang vang kurang baik }\end{array}$ \\
\hline \multirow{4}{*}{ Delivery } & 100 & $\begin{array}{l}\text { Barang yang dikirim ke pabrik } \\
\text { sebanyak } x \text { kali pemesanan dan } \\
\text { sebanyak } x \text { kali pemesanan dengan } \\
\text { semua pengiriman tepat waktu }\end{array}$ \\
\hline & 90 & $\begin{array}{l}\text { Barang dikirim ke pabrik sebanyak x } \\
\text { kali pemesanan dan } 1 \text { kali terlambat } \\
\text { kirim }\end{array}$ \\
\hline & 80 & $\begin{array}{l}\text { Barang dikirim ke pabrik sebanyak x } \\
\text { kali pemesanan dan } 2 \text { kali terlambat } \\
\text { kirim }\end{array}$ \\
\hline & 70 & $\begin{array}{l}\text { Barang dikirim ke pabrik sebanyak x } \\
\text { kali pemesanan dan } 3 \text { kali terlambat } \\
\text { kirim }\end{array}$ \\
\hline \multirow{4}{*}{$\mathrm{K} 3 \mathrm{~L}$} & 100 & $\begin{array}{l}\text { Penggunaan alat safety yang lengkap } \\
\text { saat pengiriman }\end{array}$ \\
\hline & 90 & $\begin{array}{l}\text { Penggunaan alat safety yang kurang } \\
\text { lengkap saat pengiriman }\end{array}$ \\
\hline & 80 & $\begin{array}{l}\text { Penggunaan alat safety yang minim } \\
\text { saat pengiriman }\end{array}$ \\
\hline & 70 & $\begin{array}{l}\text { Tidak penggunaan alat safety saat } \\
\text { pengiriman }\end{array}$ \\
\hline
\end{tabular}




\section{b. Tahap Pengumpulan Data}

Pengumpulan data dilakukan untuk mengetahui dan mengenal lebih lanjut keinginan dan kebutuhan perusahaan akan performansi supplier dalam melakukan pemenuhan bahan baku. Pengumpulan data untuk metode Fuzzy-Quality Function Deployment akan dilakukan menggunakan kuesioner yang akan diberikan kepada departemendepartemen yang terkait langsung dengan proses pembelian bahan baku.

\section{c. Identifikasi kriteria pemilihan supplier}

Kriteria yang digunakan dalam penelitian ini merupakan kebutuhan dan keinginan perusahaan terhadap bentuk layanan yang diberikan supplier untuk pemenuhan order. Dimana sebagian besar kriteria performansi yang ada telah dibuat berdasarkan jurnal dan masukan dari pihak perusahaan. Kriteria yang disusun dalam kuisioner disebarkan dan diisi oleh responden pada bagian departemen yang terkait untuk mendapatkan preferensi mengenai performansi supplier yang diinginkan. Dengan demikian perusahaan akan mendapatkan gambaran tentang kriteria-kriteria apa yang harus dimiliki oleh supplier.

\section{d. Pembuatan kuisioner}

Untuk mengetahui kebutuhan perusahaan maka digunakan metode kuisioner dimana metode ini cukup baik digunakan untuk menggali informasi dari responden.

Terdapat lima tahapan kuisioner yang dibuat untuk mendapatkan informasi tentang kriteria performansi supplier serta tingkat kepentingannya.

1. Mengidentifikasi kriteria-kriteria apa yang dibutuhkan perusahaan (what) dalam pemilihan supplier.

2. Mengidentifikasi bobot nilai kebutuhan perusahaan (what) dalam pemilihan supplier yang diberikan oleh pengambil keputusan.

3. Mengidentifikasi respon teknis (how) perusahaan dalam pemilihan supplier.

4. Mengidentifikasi bobot nilai antara kebutuhan perusahaan (what) dengan respon teknik (how) yang diberikan oleh pengambil keputusan,

5. Mengidentifikasi preferensi dari masingmasing supplier terhadap respon teknis (how) yang diberikan pengambil keputusan.

\section{e. Penyebaran kuisioner}

Penyebaran kuisioner ini dilakukan pada departemen-departemen yang ada di perusahaan untuk mendapatkan responden yang diinginkan. Penyebaran dilakukan terhadap 12 responden yang memenuhi syarat untuk menjawab kuisioner yang disebarkan untuk semua departemen terkait dalam proses pembelian bahan baku.

\section{f. Daftar supplier bahan baku}

Perusahaan mendapatkan bahan baku aluminium sulfat yaitu sulfur dan aluminium hidroksida dari beberapa supplier. Dimana material sulfur dan aluminium hidroksida masing-masing mempunyai empat supplier. Data nama supplier untuk sulfur dan aluminium hidroksida pada tabel 2 .

Tabel 2. Nama-nama supplier bahan baku aluminium sulfat

\begin{tabular}{|c|c|c|}
\hline Material & Supplier & Alamat \\
\hline \multirow{4}{*}{ Sulfur } & Standart Chemical Corp. PTE.LTD & Jalan Besut, Jurong 5 Singapore 619559 \\
\hline & PT. Lautan Luas & $\begin{array}{l}\text { Bukit Timah } 75 \text { Road \# 05-14. Boon Siew Bulding } \\
\text { Singapore }\end{array}$ \\
\hline & PT. Yosomulyo Jajag & Jl. Rajawali no. 84 Surabaya 60164 \\
\hline & CV. Archindo & Jl. Ametiz III/16 Bunder Asri Gresik \\
\hline \multirow{4}{*}{$\begin{array}{l}\text { Aluminium } \\
\text { hidroksida }\end{array}$} & PT. Bisindo Kencana & $\begin{array}{l}\text { Wisma Bisnis Indonesia Lt.4 Jl. Letjen.S.Parman Kav. } \\
12 \text { Jakarta } 11480\end{array}$ \\
\hline & Hindalco Industries Limited & 1, Middleton Street, Calcuta 700071, India \\
\hline & Sumitomo & $\begin{array}{l}\text { Rodovia Pocos-Andradas KM } 1037701-970-P o c o s \text { de } \\
\text { Caldas-MG-Brazil }\end{array}$ \\
\hline & Chemindus SDN BHD & $\begin{array}{l}\text { No. 20\&22, Jalan Selat Selatan 6,Off Jalan Banting, } \\
\text { Landpack Industrial Part,42000 Part Klang, Selangor } \\
\text { Darul Ehsan, Malaysia }\end{array}$ \\
\hline
\end{tabular}




\section{Fuzzy Quality Fuction Deployment}

a. Mengidentifikasi kebutuhan perusahaan (what)

Dari hasil penyebaran kuisioner yang digunakan untuk menentukan kriteria pemilihan supplier, menurut perusahaan yang dianggap perlu atau penting didapatkan 12 kriteria. Kriteria-kriteria yang sesuai dengan kebutuhan perusahaan (what) dapat dilihat pada tabel 3 .

Tabel 3. Kriteria kebutuhan perusahaan (what)

\begin{tabular}{|l|l|}
\hline No. & \multicolumn{1}{|c|}{ Kriteria } \\
\hline 1. & Mutu produk \\
\hline 2. & Harga \\
\hline 3. & $\begin{array}{l}\text { K3L } \\
\text { lingkungan) }\end{array}$ \\
\hline 4. & Ketepatan waktu pengiriman \\
\hline 5. & Sistem pembayaran \\
\hline 6. & Layanan perbaikan \\
\hline 7. & Ketersediaan dalam pemenuhan order \\
\hline 8. & Ketepatan jumlah barang \\
\hline 9. & Kelengkapan dokumen pengiriman \\
\hline 10. & Prosedur komplain \\
\hline 11. & Koordinasi informasi \\
\hline 12. & Kontrol operasi \\
\hline
\end{tabular}

\section{b. Menentukan bobot kriteria}

Setelah kriteria data terkumpul langkah selanjutnya adalah mengolah data tersebut dengan menggunakan fuzzy-QFD, dimana fuzzy yang digunakan adalah triangular fuzzy number.

Dari hasil penilaian oleh pengambil keputusan dalam bentuk triangular number fuzzy tersebut dikonversikan menjadi suatu nilai batas atas, nilai tengah dan nilai batas bawah dari fungsi keanggotaan untuk tiap-tiap responden.

Tabel 4. Skala linguistik untuk penilaian kriteria

\begin{tabular}{|l|c|}
\hline Skala linguistik & Skala bilangan Fuzzy \\
\hline Sangat tidak penting & $(0,1,2)$ \\
\hline Tidak penting & $(2,3,4)$ \\
\hline Cukup penting & $(4,5,6)$ \\
\hline Penting & $(6,7,8)$ \\
\hline Sangat penting & $(8,9,10)$ \\
\hline
\end{tabular}

c. Menentukan tingkat kepentingan kebutuhan perusahaan (what)

Kriteria-kriteria kebutuhan perusahaan (what) yang terpilih selanjutnya oleh pengambil keputusan diberikan penilaian sesuai dengan tingkat kepentingannya.

\section{d. Mengidentifikasi respon teknis (how)}

Untuk mengidentifikasi respon teknis (how) dalam pemilihan supplier ditentukan oleh manajemen perusahaan, yang mana respon teknis itu bertujuan untuk menjawab pertanyaan "bagaimana" cara manajemen perusahaan merespon kepada "apa" yang menjadi kebutuhan perusahaan dalam menentukan kriteria pemilihan supplier.

\section{e. Menentukan hubungan antar respon teknis} (how)

Pengambil keputusan akan memberi penilaian dari hubungan antar respon teknis (how). Hubungan antar respon teknis (how) ini bertujuan untuk mengetahui bagaimana perubahan respon teknis mempengaruhi respon teknis yang lainnya.

\section{f. Menentukan hubungan antara kebutuhan perusahaan (what) dan respon teknis (how)}

Pengambil keputusan akan memberikan penilaian hubungan antara kebutuhan perusahaan (what) dengan respon teknis (how) perusahaan dalam pemilihan supplier.

\section{g. Menentukan bobot respon teknis (how)}

Pengambil keputusan akan memberikan penilaian hubungan antara kebutuhan perusahaan (what) serta hubungan kebutuhan perusahaan (what) dan respon teknis (how) dalam pemilihan supplier.

\section{h. Penyusunan rumah kualitas (House of Quality)}

Setelah data-data terkumpul maka langkah selanjutnya akan dibuat diagram rumah kualitas atau HOQ yang menggambarkan keseluruhan informasi yang dibutuhkan dalam rangka mengembangkan untuk menentukan kualitas layanan dalam mengevaluasi supplier. 


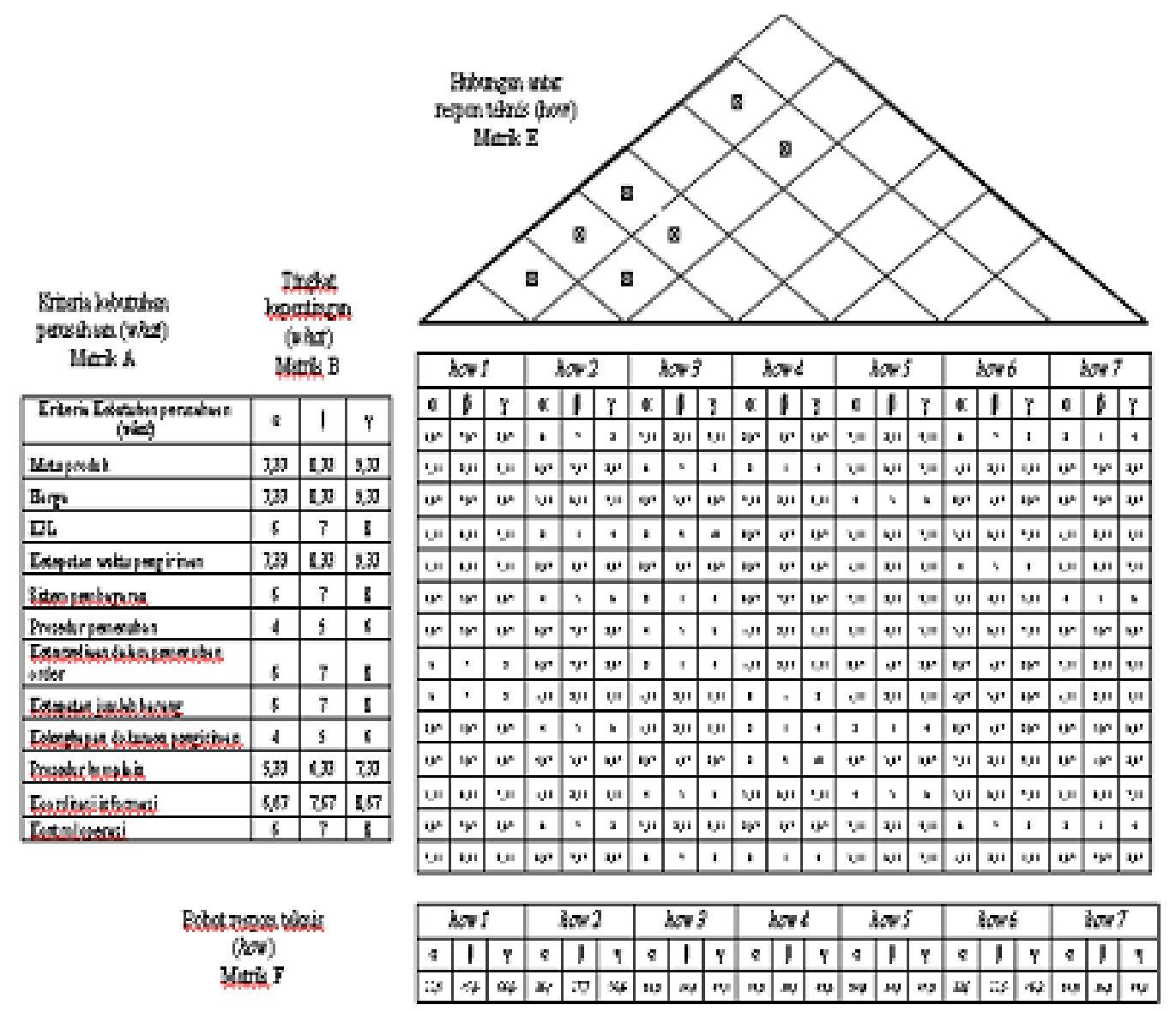

Menentukan skor masing-masing Gambar 2. House of Quality bobot respon teknis (how) perusahaan.

Tabel 5 Data hasil perhitungan FSI masing-masing supplier

\begin{tabular}{|l|l|l|l|l|}
\hline \multirow{2}{*}{ Material } & \multirow{2}{*}{ Supplier } & \multicolumn{2}{|l|}{ FSI } & \multicolumn{1}{l|}{} \\
\cline { 3 - 5 } & & $\boldsymbol{\alpha}$ & $\boldsymbol{\beta}$ & $\gamma$ \\
\hline \multirow{4}{*}{ Sulfur } & Standart Chemical Corp. PTE.LTD & 84,6 & 157,2 & 257,9 \\
\cline { 2 - 5 } & PT. Lautan Luas & 109,8 & 193,3 & 306,9 \\
\cline { 2 - 5 } & PT. Yosomulyo Jajag & 81,3 & 153,0 & 253,9 \\
\cline { 2 - 5 } & CV. Archindo & 75,5 & 145,2 & 242,0 \\
\hline \multirow{3}{*}{$\begin{array}{l}\text { Aluminium } \\
\text { hidroksida }\end{array}$} & PT. Bisindo Kencana & 64,9 & 128,9 & 220,4 \\
\cline { 2 - 5 } & Hindalco Industries Limited & 97,7 & 178,9 & 288,6 \\
\cline { 2 - 5 } & Sumitomo & 121,7 & 211,6 & 331,3 \\
\cline { 2 - 5 } & Chemindus SDN BHD & 86,8 & 160,6 & 255,7 \\
\hline
\end{tabular}

\section{b. Hasil skor atau rangking masing-masing supplier}

Setelah semua perhitungan dilakukan maka langkah selanjutnya adalah menentukan skor dan rangking dari masing-masing supplier. Hasil skor dan rangking dari masing-masing supplier dapat dilihat di tabel 6 . 
Tabel 6 Data hasil skor dan rangking supplier

\begin{tabular}{|l|l|c|c|}
\hline Material & Supplier & Skor & Rangking \\
\hline \multirow{4}{*}{ Sulfur } & Standart Chemical Corp. PTE.LTD & 164,3 & 2 \\
\cline { 2 - 4 } & PT. Lautan Luas & 200,8 & 1 \\
\cline { 2 - 4 } & PT. Yosomulyo Jajag & 160,3 & 3 \\
\cline { 2 - 4 } & CV. Archindo & 152,0 & 4 \\
\hline \multirow{3}{*}{$\begin{array}{l}\text { Aluminium } \\
\text { hidroksida }\end{array}$} & PT. Bisindo Kencana & 186,0 & 2 \\
\cline { 2 - 4 } & Hindalco Industries Limited & 219,0 & 1 \\
\cline { 2 - 4 } & Sumitomo & 165,9 & 3 \\
\cline { 2 - 4 } & Chemindus SDN BHD & 135,8 & 4 \\
\hline
\end{tabular}

Hasil perhitungannya dalam menentukan skor dan rangking masing-masing supplier. Untuk lebih jelasnya skor dari supplier sulfur dapat dilihat gambar 3

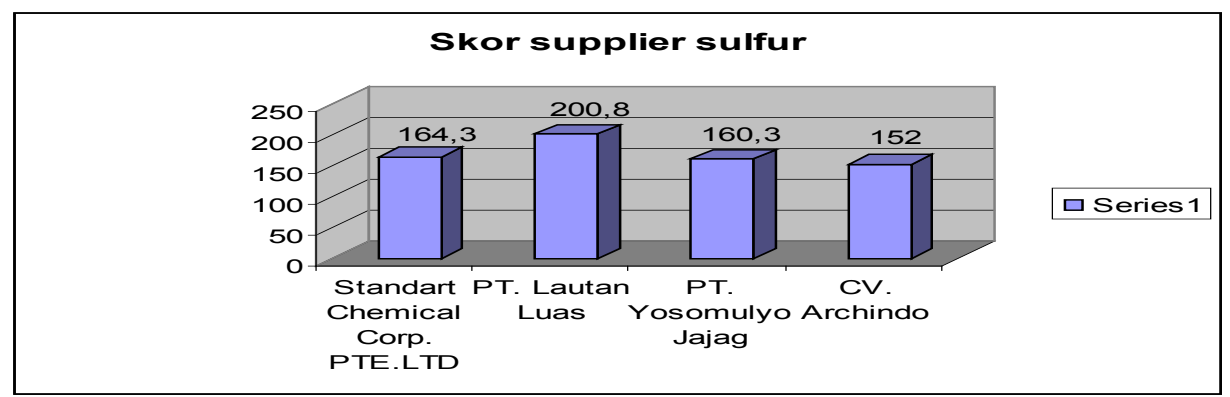

Gambar 3. Skor supplier sulfur

Berdasarkan gambar 3 dapat diketahui supplier sulfur yang mempunyai skor tertinggi sebesar 200,8 adalah PT. Lautan Luas.
Sedangkan skor untuk supplier aluminium hidroksida dapat dilihat pada gambar 4 .

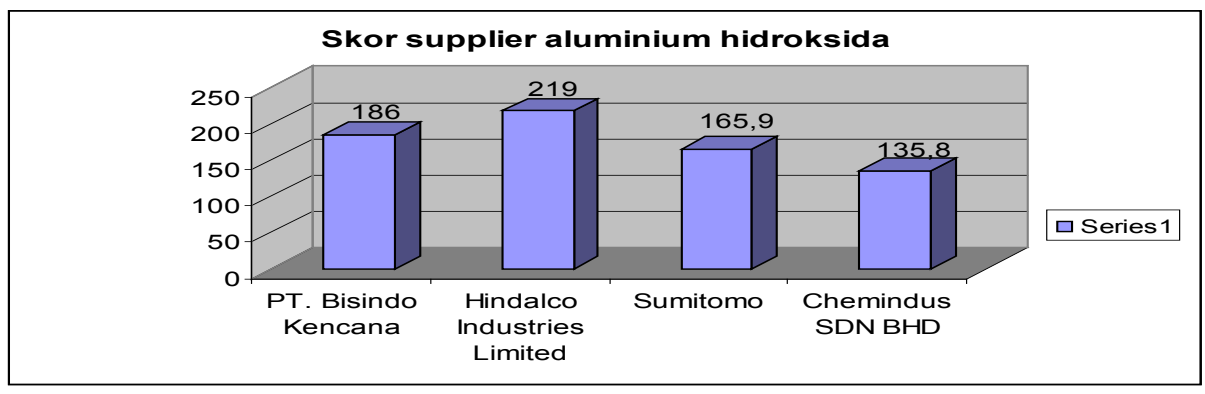

Gambar 4. Skor supplier Aluminium Hidroksida

Berdasarkan gambar 4 dapat diketahui supplier aluminium hidroksida yang mempunyai skor tertinggi sebesar 219 adalah Hindalco Industries Limited.

\section{KESIMPULAN}

1. Terdapat 12 kriteria kebutuhan perusahaan (what) dan 7 respon teknis (how) yang dapat digunakan untuk mengukur performansi supplier dalam memenuhi order PT. Liku Telaga.

1. Ada 12 kriteria kebutuhan perusahaan (what) yaitu: mutu produk, harga, K3L (keselamatan kesehatan kerja dan lingkungan), Ketepatan waktu pengiriman, system pembayaran, layanan perbaikan, ketersediaan dalam pemenuhan order, ketepatan jumlah barang, kelengkapan dokumen pengiriman, prosedur komplian, koordinasi informasi, dan kontrol operasi.

3. Ada 7 respon teknis (how) yaitu: pengalaman, pemenuhan kapasitas, sertifikasi system quality, merespon pemesanan customer, kondisi keuangan, system komunikasi, dan lokasi.

4. Skor masing-masing supplier sulfur adalah PT. Lautan Luas (Singapore) dengan skor 200,8, Standart Chemical Corp. PTE.LTD 
(Singapore) dengan skor 164,3, PT. Yosomulyo Jajag (Surabaya) dengan skor 160,3 dan CV. Archindo (Gresik) dengan skor 152,0

5. Skor masing-masing supplier aluminium hidroksida adalah Hindalco Industries Limited (India) dengan skor 219,0, PT. Bisindo Kencana (Jakarta) dengan skor 186,0, Sumitomo (Brazil) dengan skor 165,9, dan Chemindus SDN BHD (Malaysia) dengan skor 135,8.

\section{DAFTAR PUSTAKA}

Alifulllah (2008). Pemilihan Supplier dan Alokasi Order menggunakan Pendekatan Taguchi Loss Function-AHP-Fuzzy Multiobjective Integer Programming. Tugas Akhir Sarjana, ITS, Surabaya.

Bevilacqua, M. Ciarapica, F, E. dan Giacchetta, G. (2006). A Fuzzy-QFD Approach to Supplier Selection. Journal of Purchasing \& Supply Management 12, 14-27.

Boer, L. Labro, E. dan Morlacchi, P.(2001). A Review of Methods Supporting Supplier Selection. Journal of Purchasing \& Supply Management 7, 75-89.

Ciptomulyono, U. (1996), “Model Fuzzy Goal Programming Untuk Perencanaan Produksi Terpadu”, IPTEK, November, hal 116-127.

Cohen, L. (1995). Quality Function Deployment, How to make QFD Work for you. Addison Wesley Publishing Company, Massachuset.

Dhuto, S. U. (2005). Usulan Pemilihan Supplier Bahan Baku dengan Penggabungan Metode TOPSIS dan AHP, Thesis, ,ITS, Surabaya.

Kahraman, C. Ertay, T. dan Buyukozkan, G. (2006). A Fuzzy Optimization Model for QFD Planning Process using Analytic Network Approach. European Journal of Operational Research 7, 390-411.

Kusumadewi, S. (2004). Aplikasi Logika Fuzzy untuk Pendukung Keputusan. Graha Ilmu, Yogyakarta.

Lieberman, G.J. dan Hillier, F.S. (1990). Introduction to Operations Research. McGraw-Hill, Singapore.

Muflih, 2005. Alokasi Order pada Supplier dengan Pendekatan Metode Quality Function Deployment dan Linear Programming. Thesis.
ITS, Surabaya.

Papandreou, V. dan Shang, Z. (2008),"Multi Criteria Optimation Approach for the design of sustainable Utility System", Computer and Chemical Engineering, vol 32, 1589-1602.

Pujawan, N, I. (2005). Supply Chain Management. Guna Widya, Indonesia.

Sanayei, A, S. dan Mousavi, F, S. Abdi, M, R. Mohaghar, A. (2008). An Intregrated Group Decision-Making Process for Supplier Selection and Order Allocation Using Multi-Attribute Utility Theory and Linear Programming. Journal of the Franklin Institute 345, 731-747.

Tabucanon, Mario T. (1988). Multiple Criteria Decision Making in Industry. Division of Industrial Engineering and Management, Asian Institute of Technology, Bangkok, Thailand.

Verma, R. dan Pullman, M.E., (1998a). An Analysis of The Supplier Selection Process. International Journal of Management Sci. 26 (6), 739-750.

Temponi C.,Yen J. dan Tiao W.A., (1999). House of Quality: A fuzzy Logic-Based Requirement Analysis. European Journal of Operational Research 117, 340-354.

Weber, C., Current, J.R. dan Benton, W.C. (1991). Vendor Selection Criteria and Methods. European Journal of Operational Research 50, 2-18.

Yogi, K, N. (2004). Evaluasi Kinerja Supplier dan Alokasi Volume Pembelian di PT. NE. Thesis. ITS, Surabaya.

Zadeh, L.A. (1965). Fuzzy sets. Information and Control 8, 338-353. 